\title{
Embryotoxicity of Yangambin Isolated from Ocotea duckei Vattimo-Gil in Gallus gallus domesticus Embryos
}

\author{
Thiago Felix da Silva ${ }^{1, *}$, Maria Isabel de Assis Lima Castro ${ }^{2}$, Marta Gerusa Soares de Lucena ${ }^{3}$, Camilla Vila Nova \\ Soares Silva ${ }^{4}$, Laisla Rangel Peixoto ${ }^{5}$, Eliane Alves Bandeira de Carvalho ${ }^{6}$, Silvania Tavares Paz ${ }^{7}$, Beathryz \\ Lethycya Almeida Guimarães ${ }^{3}$, José Maria Barbosa Filho ${ }^{8}$, Eliete Cavalcanti da Silva'
}

\begin{abstract}
Thiago Felix da Silva ${ }^{1, *}$, Maria Isabel de Assis Lima Castro ${ }^{2}$, Marta Gerusa Soares de Lucena ${ }^{3}$, Camilla Vila Nova Soares Silva ${ }^{4}$, Laisla Rangel Peixoto ${ }^{5}$, Eliane Alves Bandeira de Carvalho ${ }^{6}$, Silvania Tavares $\mathrm{Paz}^{7}$, Beathryz Lethycya Almeida Guimarães ${ }^{3}$, José Maria Barbosa Filho ${ }^{8}$, Eliete Cavalcanti da Silva ${ }^{1}$
\end{abstract}

'Postgraduate Program in MorphotechnologyFederal University of Pernambuco, Recife, $P E$, BRAZIL.

${ }^{2}$ Master of Sciences; Postgraduate Program in Biological Sciences - Federal University of Pernambuco, Recife, PE, BRAZIL. ${ }^{3}$ Department of Histology and Embryology - Federal University of Pernambuco, Recife, PE, BRAZIL.

${ }^{4}$ Multiprofessional Residency Program in Health Surveillance - Recife Health Department, Recife, PE, BRAZIL.

${ }^{5}$ Master of Sciences; Institute of Drugs and Medicines Research - Federal University of Paraíba, João Pessoa, PB, BRAZIL.

${ }^{6}$ Master of Sciences; Postgraduate Program in Biological Sciences - Federal University of Pernambuco, Recife, PE, BRAZIL.

${ }^{7}$ Master of Sciences; Department of

Pathology - Federal University of

Pernambuco, Recife, PE, BRAZIL.

${ }^{8}$ Institute of Drugs and Medicines Research Federal University of Paraíba, João Pessoa, PB, BRAZIL.

\section{Correspondence}

\section{Prof. Thiago Felix da Silva}

Graduate, Postgraduate Program in Morphotechnology - Federal University of Pernambuco, CEP: 50.760 420, Recife, PE, BRAZIL.

Phone no: +55 (81) 99817-4541

Email id: thiagofelix.felix@hotmail.com

\section{History}

- Submission Date: 30-03-2021;

- Review completed: 15-05-2021;

- Accepted Date: 04-06-2021

DOI : 10.5530/pres.13.3.5

Article Available online http://www.phcogres.com

\section{Copyright}

(C) 2021 Phcog.Net. This is an openaccess article distributed under the terms of the Creative Commons Attribution 4.0 International license.

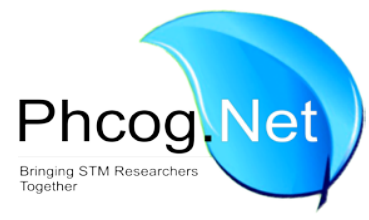

\begin{abstract}
Introduction: Yangambin, a lignan predominant in the leaves of Ocotea duckei Vattimo-Gil, has several biological activities, such as anti-convulsant, analgesic, anti-inflammatory and leishmanicidal. Objectives: The aim of this study was to evaluate the embryotoxicity of yangambin on the neurodevelopment of Gallus gallus domesticus embryos. Materials and Methods: 120 fertilized eggs were divided in three groups: G1 (PBS with $0.1 \%$ Tween 80), $\mathrm{G} 2(50 \mu \mathrm{g} / \mathrm{ml}$ yangambin) and $\mathrm{G} 3(65 \mu \mathrm{g} / \mathrm{ml}$ yangambin) and each egg was inoculated with $100 \mu \mathrm{L}$ of the respective solutions. The fertilized eggs were incubated at a temperature of $37.5^{\circ} \mathrm{C}$, with a relative humidity of $65 \%$ to $75 \%$, for $48 \mathrm{hr}$ and then their embryos were histologically processed. Results: In staging, carried out according to Hamburger and Hamilton (1951), variations of stages were identified. In all groups, the morphological analysis revealed the closure of the anterior neuropore and absence of malformations in the optic vesicles and in the secondary encephalic vesicles. In the caudal region, a standard development of the neural tube was observed, with well-segmented somites and regression of the primitive line. The cross sections showed that the internal structure of the somite's, composed of dermatome, myotome and sclerotome, was preserved. The statistical analysis did not show significant differences between the groups regarding the morphometry of the cephalic and caudal regions of the neural tube. Conclusion: Yangambin did not show embryotoxic effects on the neurodevelopment of Gallus gallus domesticus embryos, under the tested conditions. Key words: Chicken embryo, Lauraceae, Lignan, Neurodevelopment, Secondary metabolites.
\end{abstract}

\section{INTRODUCTION}

Plants synthesize chemical compounds that are classified as primary and secondary metabolites. ${ }^{[1]}$ The secondary metabolites of plants are divided into terpenes, alkaloids and phenolic compounds. ${ }^{[2]}$ In the group of phenolic compounds are lignan's that give rigidity to woody species, in addition to protection in situations of mechanical injuries and invasion by fungi or bacteria. ${ }^{[3]}$ Lignans are present in Ocotea duckei Vattimo-Gil (Lauraceae), popularly known as "Louro-de-cheiro", "Louro-pimenta" or "Louro-canela" and is widely distributed in the Northeast of Brazil, having in its leaves a furofuran lignan, called yangambin, which is the major constituent of the total fraction of lignoids of the species. ${ }^{[4-6]}$

Yangambin has pharmacological effects; analgesic activity, ${ }^{[7]}$ apoptosis induction in tumor cells, ${ }^{[8]}$ antiPAF, ${ }^{[9]}$ anti-inflammatory, ${ }^{[10]}$ vasorelaxant and hypotensive, ${ }^{[11]}$ as well as leishmanicidal. ${ }^{[12,13]}$

The therapeutic potential of medicinal plants is related to natural products, which are sources of several bioactive molecules and when isolated, their biological activities can be investigated through experimental models. ${ }^{[14,15]}$ However, itisnecessarytoincludetoxicity tests to identify the effects of the interaction between these compounds and the organism, in addition to ensuring that these substances do not cause harmful effects. ${ }^{[16]}$

Embryos of the species Gallus gallus domesticus have been used as an experimental model of embryotoxicity. ${ }^{[17,18]}$ The morphological similarity with mammalian embryos and the high sensitivity to the action of chemical agents, especially at the beginning of development, due to intense cell proliferation, contribute to the use of this species in toxicity tests. ${ }^{[19]}$ Present as advantages low maintenance cost, easy handling and development outside the maternal organism..$^{[20,21]}$ In addition, present well-documented stages of their ontogenesis. ${ }^{[22]}$ Therefore, investigations of embryotoxicity of yangambin, isolated from Ocotea duckei Vattimo-Gil, on the neurodevelopment of Gallus gallus domesticus embryos, through morphological and morphometrical analysis are our objectives.
Cite this article: Silva TF, Castro MI, Lucena MG, Silva CV, Peixoto LR, Carvalho EA, Paz ST, Guimarães BL, Filho JM, Silva EC. Embryotoxicity of Yangambin Isolated from Ocotea duckei Vattimo-Gil in Gallus gallus domesticus Embryos. Pharmacog Res. 2021;13(3):135-9. 


\section{MATERIALS AND METHODS}

\section{Yangambin}

Yangambin was isolated from the leaves of Ocotea duckei Vattimo-Gil collected in the municipality of Santa Rita, Paraíba State, Brazil. An exsiccata of this species is deposited at the Federal University of Paraíba (AGRA 4309). Extraction and isolation were performed according to Castro et al. ${ }^{[23]}$

\section{Gallus gallus domesticus embryos}

COBB lineage eggs, with $24 \mathrm{hr}$ of fertilization, were kindly provided by G3 Agroavícola, located at Fazenda Santa Teresinha, Riacho das Almas, Pernambuco State, Brazil ( $8^{\circ} 08^{\prime} 23.0^{\prime \prime S} 35^{\circ} 51^{\prime} 52.1^{\prime \prime}$ ). 120 eggs were used, being separated into three groups, containing 20 eggs each. The experiment was carried out in duplicate. G1 - pH 7.0 Phosphate buffered saline with $0.1 \%$ Tween 80 (control); G2 - $50 \mu \mathrm{g} / \mathrm{ml}$ yangambin and G3 - $65 \mu \mathrm{g} / \mathrm{ml}$ yangambin. The determination of yangambin concentrations was in accordance with the $\mathrm{IC}_{50}$ values for Leishmania spp described in the literature. ${ }^{[12,13]}$ After the inoculation of experimental solutions in the air chamber, the eggs were sealed with adhesive tape, identified and incubated at $37.5^{\circ} \mathrm{C}$, relative humidity of $65 \%$ to $75 \%$, for $48 \mathrm{hr}$. After this period, the embryonated eggs were desensitized for $20 \mathrm{~min}$ at $20^{\circ} \mathrm{C}$. The protocol of this study with Gallus gallus domesticus embryos was analyzed and approved by the Ethics Committee on the Use of Animals of the Bioscience Center - Federal University of Pernambuco (process n. $\left.{ }^{\circ} 23076.010939 / 2018-31\right)$.

\section{Histological processing}

The processing of the embryos followed the methodology adapted from Kmecick et al. ${ }^{[19]}$ Embryonic discs were removed with the aid of finetipped scissors and transferred to a Petri dish, containing distilled water, to remove calf excess and fixed in Bouin for two hours, being stored in $70 \%$ ethanol at room temperature. For the total assembly technique, the embryos were hydrated with distilled water and stained with Hematoxylin for $30 \mathrm{sec}$, dehydrated in an increasing series of ethanol (70\%, 80\%, $90 \%$ and $100 \%$ ) for $30 \mathrm{~min}$ and diaphanized with xylol. Subsequently, the samples were assembled with Canada balsam.

In the cross-sectional technique adapted from Turgut et al. ${ }^{[24]}$ the embryos were submitted to increasing concentrations of ethanol for $30 \mathrm{~min}$ and diaphanized with xylol for $10 \mathrm{~min}$. Then, embedded in paraffin at $60^{\circ} \mathrm{C}$ for $10 \mathrm{~min}$. The blocks were cut to $4 \mu \mathrm{m}$ thick in a microtome, stained with Hematoxylin/Eosin and dehydrated in increasing concentrations of ethanol, being diaphanized with xylol for two minutes and for assembling the preparations, Entellan ${ }^{\circledR}$ was used.

\section{Morphological and morphometrical analysis}

Images were captured with an optical microscope attached to a digital camera (MOTICAM 1000 1.3M Pixel - USB 2.0, QUIMIS) using the MOTIC Image plus 2.0 Software. Staging, used to estimate the age of embryos, followed the model proposed by Hambuger and Hamilton. ${ }^{[22]}$ A qualitative morphological analysis of the following structures was performed: brain and optical vesicles, neural tube and somites.

In the morphometrical analysis, using the embryological preparations of the total assembly technique, the width of the neural tube was measured in all embryos belonging to stage 14 . To identify possible defects in the neural tube, a straight line was drawn at three equidistant points. To standardize the analysis, the $9^{\text {th }}, 11^{\text {th }}$, and $13^{\text {th }}$ somite pairs were defined. The width of the cephalic region was measured with reference to the diencephalon and the optic vesicle in formation.

\section{Statistical analysis}

The statistical analysis of the data from the morphometry in the total assembly technique was performed using the GraphPad Prism 7.0 software. The Analysis of Variance test (ANOVA) was used, followed by the Tukey test with a significance level of $5 \%(P<0.05)$.

\section{RESULTS AND DISCUSSION}

The possible embryotoxic effects of yangambin were investigated through the morphological and morphometrical analysis of neurodevelopment and somites.

The 48-hr incubation of the 60 fertilized eggs, designated for the total assembly technique, resulted in 45 embryonated eggs, which can be explained by the incubation yield rate, which may vary according to the fertility of the eggs, the handling and the incubator conditions. ${ }^{[25,26]}$

In the 45 embryos, stages 13,14 and 15 were shown, according to the model proposed by Hamburger and Hamilton. ${ }^{[22]}$ Our findings corroborate with studies in which variations of the stages were observed, within the same period of time and incubation conditions. ${ }^{[27,19,28]}$ This demonstrates that it is common to occur variations between embryos, due to some factors such as egg laying, storage and incubation, temperature fluctuations and also due to the species genetics. ${ }^{[29,30]}$

The embryos of the total assembly technique presented the five secondary encephalic vesicles (telencephalon, diencephalon, mesencephalon,

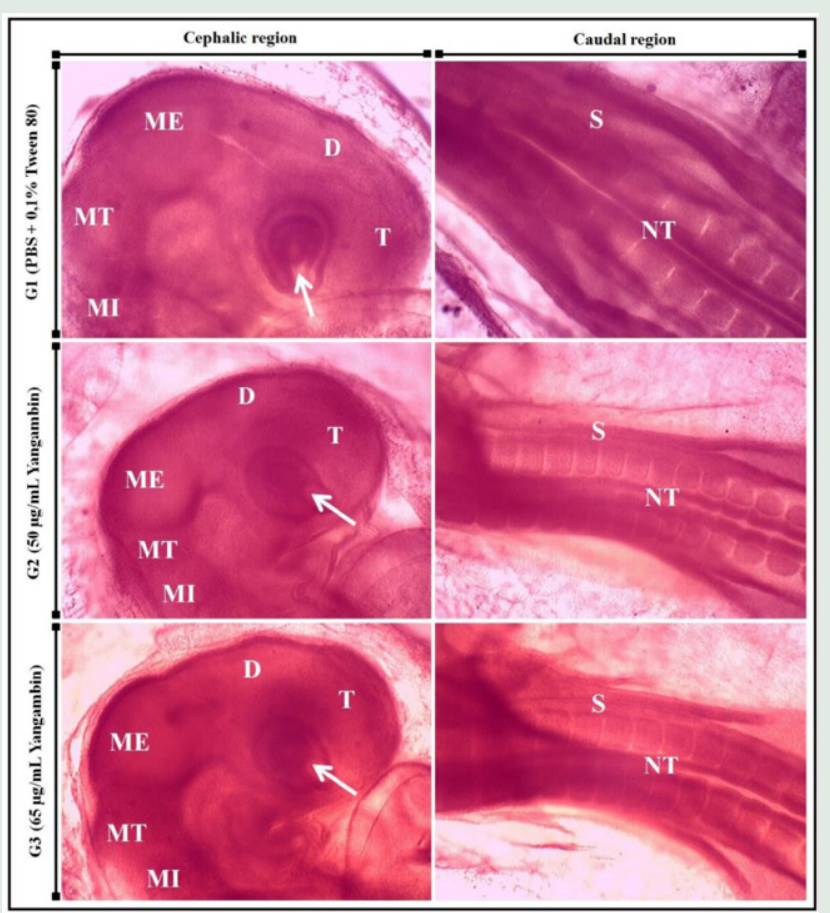

Figure 1: Photomicrograph of Gallus gallus domesticus embryos, processed by the total assembly technique, incubated for $48 \mathrm{hr}$, at stage 14 . In the cephalic region, the presence of secondary encephalic vesicles is noted: telencephalon ( $T$ ), diencephalon (D), mesencephalon (ME), metencephalon (MT) and myelencephalon (MI), which present normal morphology in both groups; the optical vesicles indicated by the arrow can also be viewed. In the caudal region of the embryo, the somites (S) are well segmented and the neural tube (NT) has no malformations. Hematoxylin staining. 100x magnification. 
metencephalon and myelencephalon) (Figure 1). According to Ishikawa et al. ${ }^{[31]}$ the appearance in sequence of primary and subsequently secondary brain vesicles corresponds to the standard development of the central nervous system, as observed in this essay, suggesting the non-interference of yangambin in the early stages of neurodevelopment.

The anterior neuropore of all embryos closed completely, corroborating the morphology described by Hamburger and Hamilton. ${ }^{[22]}$ As opposed to our study, in embryos treated with okadaic acid, an irregular closure of the anterior neuropore was identified. ${ }^{[32]}$ According to Liu et al. ${ }^{[33]} \mathrm{a}$ possible consequence of incomplete closure of the cephalic region of the neural tube is anencephaly, a malformation in which most of the brain and skull are absent. This malformation was observed by Özeren et al. ${ }^{[34]}$ when analyzing embryos treated with flurbiprofen. In addition, hydrocephalus caused by the excess of cerebrospinal fluid in the brain vesicles can also occur, which justifies the investigation of the closure of the anterior neuropore. ${ }^{[35]}$

The optic vesicles also showed normal morphology in all embryos, this is an indication of the absence of malformation in the prosencephalon, primary encephalic vesicle, since the development of the optic vesicles is dependent on the development of the prosencephalon as described by Hirashima et al. ${ }^{[36]}$

Along the neural tube, in the embryos of all groups, the somites presented normal segmentation, with no malformations being observed. Emon

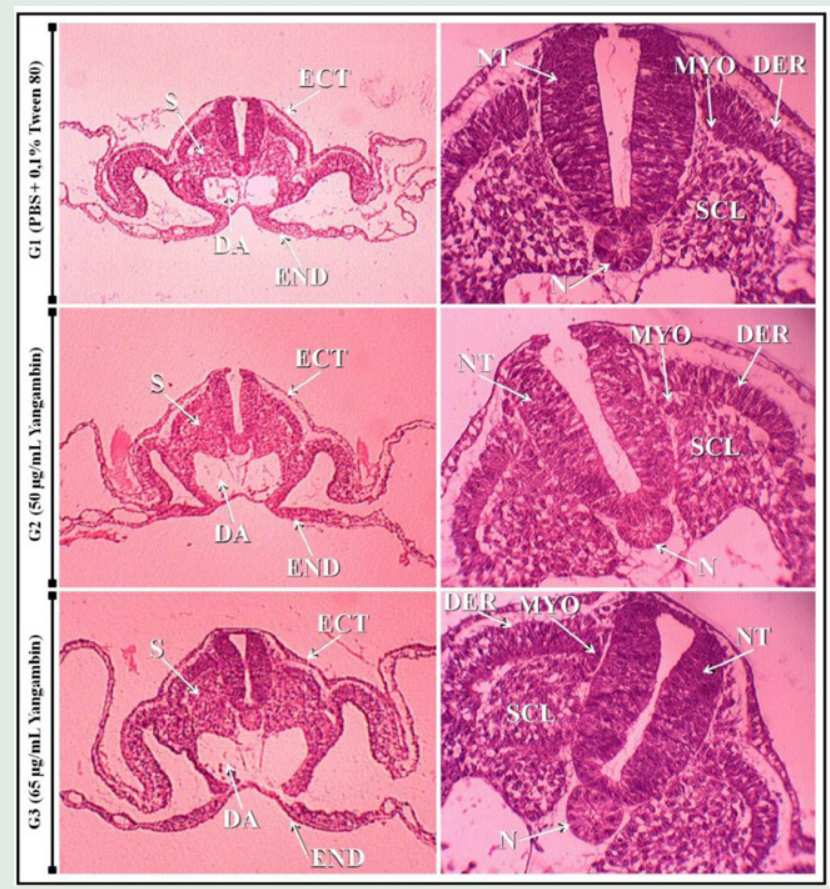

Figure 2: Photomicrograph of Gallus gallus domesticus embryos, processed by the cross-sectional technique, incubated for $48 \mathrm{hr}$. The germ layers can be viewed: ectoderm (ECT) and endoderm (END), and the somite $(S)$ in the process of differentiation with normal morphology, and the dorsal aorta (DA) in the process of formation. $100 x$ magnification. Note the roof plate and floor plate of the neural tube (NT) with thin thickness; the notochord (N) has a normal delimitation; it is also possible to visualize the somite divided into dermatome (DER), myotome (MYO) and sclerotome (SCL). 400x magnification. Hematoxylin - eosin stain.

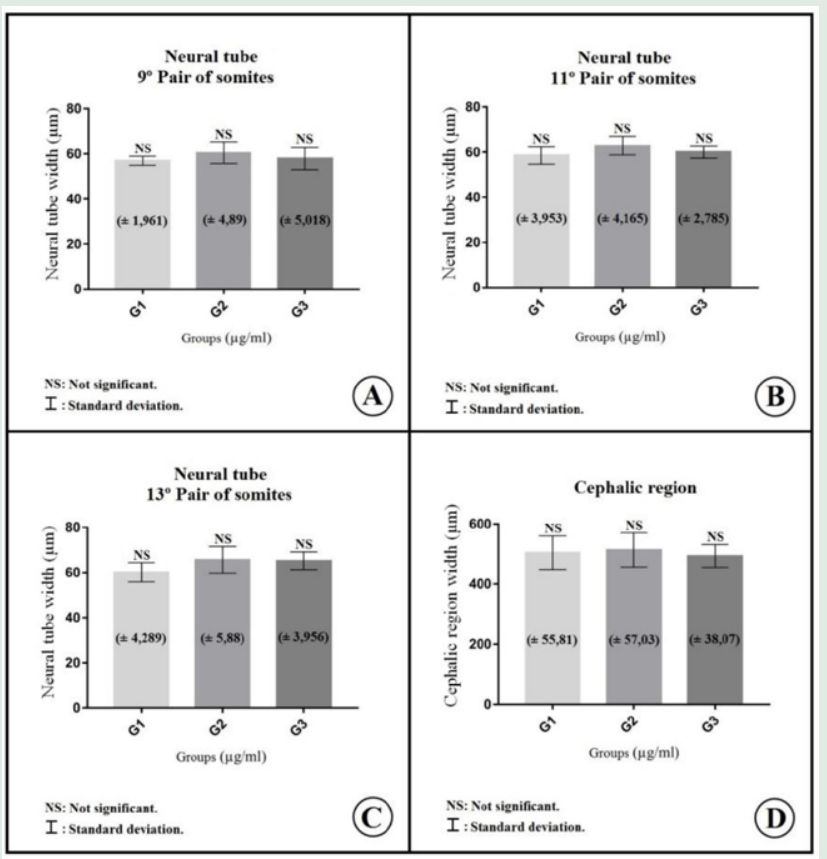

Figure 3: Statistical analysis of neural tube and cephalic region morphometry of Gallus gallus domesticus embryos, incubated for $48 \mathrm{hr}$, at stage 14 . In A, B and C, measurements of the neural tube width are observed at the height of the $9^{\text {th }}, 11^{\text {th }}$ and $13^{\text {th }}$ pair of somites, respectively. In $D$, the measurements of the cephalic region are observed. G1 - Control. G2 - $50 \mu \mathrm{g} / \mathrm{ml}$ yangambin. G3 - $65 \mu \mathrm{g} / \mathrm{ml}$ yangambin. Standard deviation ( \pm ).

et al. ${ }^{[37]}$ obtained similar results, in which the somites of embryos treated with sodium benzoate had normal delineations and the neural tube did not present malformations. The occurrence of failures during the process of somatic segmentation can result in axial skeletal malformations and irregular vertebral segmentation. ${ }^{[38,39]}$

Furthermore, according to Lee and Gleeson, ${ }^{[40]}$ failures during the closing of the neural tube region cause an anomaly called spina bifida. This malformation, characterized by the protrusion of the spinal cord, can cause physical deficiencies in the postnatal period, which demonstrates the concern to investigate the caudal region of the neural tube. ${ }^{[41]}$

At the end of the caudal region of all embryos, there was a regression of the Hensen's node, demonstrating that there was no persistence of the primitive line. According to Cinelli et al. ${ }^{[42]}$ when the primitive line does not regress properly, a rare tumor is formed at the base of the coccyx, called sacrococcygeal teratoma, which contains derivatives from the three germ layers. The presence of this tumor in the postnatal period can compromise the intestinal and urological functions and cause eventual difficulties in locomotion, which justifies the investigation of the effects of yangambin on the primitive line. ${ }^{[43]}$

In the cross-sectional technique, preserved somite structures were observed in all groups, making it possible to visualize the delimitations between dermatome, myotome and sclerotome, with no tissue damage being observed (Figure 2). Different from our study, Duess et al. ${ }^{[39]}$ when evaluating the effects of Y-27632 compound, a derivative of pyridine, observed well-defined somites, in contrast, the sclerotome presented more dissociated cells with high cell death. Our findings suggest that yangambin does not interfere with the differentiation of somite structures. 
The statistical analysis carried out from the morphometrical data of the neural tube and the cephalic region showed that the embryos incubated for $48 \mathrm{hr}$ in groups G1, G2 and G3, belonging to stage 14, did not present significant differences (Figure 3).

In the neural tube, at the height of the $9^{\text {th }}$ pair of somites, there was no statistical difference between the groups, being G1 vs G2 ( $p=0.2077), \mathrm{G} 1$ vs G3 ( $p=0.8879)$ and G2 vs G3 $(p=0.4854)$. At the height of the $11^{\text {th }}$ pair of neural tube somites, there was no statistical difference between the groups, being G1 vs G2 ( $p=0.0818), \mathrm{G} 1$ vs G3 ( $p=0.7543)$ and G2 vs $\mathrm{G} 3(p=0.3613)$. At the height of the $13^{\text {th }}$ pair of somites, there was no statistical difference between the groups, being G1 vs G2 ( $p=0.0853), \mathrm{G} 1$ vs G3 ( $p=0.1559)$ and G2 vs G3 ( $p=0.9854)$.

In the cephalic region there was also no statistical difference between the groups, being G1 vs G2 ( $p=0.9341), \mathrm{G} 1$ vs G3 $(p=0.9182)$ and G2 vs G3 $(p=0.7545)$.

The statistical results of embryo morphometry corroborated with the morphology observation data. Lima et al. ${ }^{[27]}$ when observing embryos treated with riparin III, an alkaloid from Aniba riparia (Lauraceae), found no defects in the neural tube through morphological analysis. On the other hand, in the morphometrical analysis, they identified a statistically significant increase in the width of the neural tube in all tested concentrations.

\section{CONCLUSION}

According to morphological and morphometrical results, yangambin did not show embryotoxic effects under the experimental conditions. Future studies should be conducted to ensure its pharmacological use.

\section{ACKNOWLEDGEMENT}

The authors would like to thank the company G3 Agroavícola for the free supply of fertilized eggs used in this research.

\section{Financial support and sponsorship}

Nil.

\section{CONFLICT OF INTEREST}

The authors declare no conflicts of interest.

\section{ABBREVIATIONS}

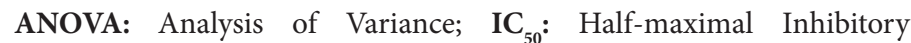
Concentration; PBS: Phosphate Buffered Saline; pH: Potential Hydrogen.

\section{REFERENCES}

1. Shih PM. Towards a sustainable bio-based economy: Redirecting primary metabolism to new products with plant synthetic biology. Plant Sci. 2018;273:84-91.

2. Bezera JWA, Rodrigues FC, Costa AR, Cunha FAB, Silva VB, Boligon AA, et al. Mesosphaerum suaveolens (L.) Kuntze (bamburral): Medicinal plant with antioxidant potential and rich in polyphenols. Rev Cuba Plant Med. 2018;24:1-15.

3. Souza VA, Nakamura CV, Corrêa AG. Antichagasic activity of lignans and neolignans. Rev Virtual Quím. 2012;4(3):197-207.

4. LiY, Xie S, Ying J, Wei W, Gao K. Chemical structures of lignans and neolignans isolated from Lauraceae. Molecules. 2018;23(12):3164.

5. Monte-neto RL, Sousa LMA, Dias CS, Barbosa-filho JM, Oliveira MR. Yangambin cytotoxicity: A pharmacologically active lignan obtained from Ocotea duckei Vattimo (Lauraceae). Z Naturforsch C J Biosci. 2008;63(9-10):681-6.

6. Antonio AS, Veiga-junior VF, Wiedemann LSM. Ocotea complex: A metabolomic analysis of a lauraceae genus. Phytochemistry. 2020;173:112314.

7. Almeida RN, Pachú CO, Barbosa-filho JM. Evaluation of the possible analgesic activity of yangambin obtained from Ocotea duckei Vattimo. Cienc Cult Saúde. 1995; 14:7-10.

8. Hausott B, Greger H, Marian B. Naturally occurring lignans efficiently induce apoptosis in colorectal tumor cells. J Cancer Res Clin Oncol 2003;129(10):569-76.

9. Jesus-morais CMQ, Assis EF, Cordeiro RSB, Barbosa-filho JM, Lima WT, Silva ZL, et al. Yangambin, a lignan obtained from Ocotea duckei differentiates putative PAF receptor subtypes in the gastrointestinal tract of rats. Planta Med. 2000;66(03):211-6.

10. Kim JY, Lim HJ, Lee DY, Kim JS, Kim DH, Lee HJ, et al. In vitro anti-inflammatory activity of lignans isolated from Magnolia fargesii. Bioorg Med Chem Lett. 2009;19(3):937-40

11. Araújo IGA, Silva DF, Alustau MC, Dias KLG, Cavalcante KVM, Veras RC, et al. Calcium influx inhibition is involved in the hypotensive and vasorelaxant effects induced by yangambin. Molecules. 2014;19(5):6863-76.

12. Monte-neto RL, Barbosa-filho JM, Sousa LMA, Athayde-filho PF, Dias CS Oliveira MR. Crude ethanolic extract, lignoid fraction and yangambin from Ocotea duckei (Lauraceae) show antileishmanial activity. Z Naturforsch C 2007;62(5-6):348-52.

13. Monte-neto RL, Sousa LMA, Dias CS, Barbosa-filho JM, Oliveira MR, Figueiredo RCBQ. Morphological and physiological changes in Leishmania promastigotes induced by yangambin, a lignan obtained from Ocotea duckei. Exp Parasitol. 2011;127(1):215-21.

14. Boy HIA, Rutilla AJH, Santos KA, Ty AMT, Yu Al, MahboobT, et al. Recommended Medicinal Plants as Source of Natural Products: A Review. Digit Chin Med 2018;1(2):131-42.

15. Mahajan M, Kuiry R, Pal PK. Understanding the consequence of environmental stress for accumulation of secondary metabolites in medicinal and aromatic plants. J Appl Res Med Aromat Plants. 2020;18:100255

16. Dutra RC, Campos MM, Santos ARS, Calixto JB. Medicinal plants in Brazil: Pharmacological studies, drug discovery, challenges and perspectives. Pharmacol Res. 2016;112:4-29.

17. Yamamoto FY, Neto FF, Freitas PF, Ribeiro CAO, Ortolani-machado CF. Cadmium effects on early development of chick embryos. Environ Toxicol Pharmacol. 2012;34(2):548-55.

18. Hutchins EJ, Bronner ME. Draxin alters laminin organization during basement membrane remodeling to control cranial neural crest EMT. Dev Biol. 2019;446(2):151-8.

19. Kmecick M, Costa MCV, Ribeiro CAO, Ortolani-machado CF. Morphological evidence of neurotoxic effects in chicken embryos after exposure to perfluorooctanoic acid (PFOA) and inorganic cadmium. Toxicol. 2019;427:152286.

20. Vancamp P, Darras VM. Dissecting the role of regulators of thyroid hormone availability in early brain development: Merits and potential of the chicken embryo model. Mol Cell Endocrinol. 2017;459:71-8.

21. Kohl A, Golan N, Cinnamon Y, Genin O, Chefetz B, Sela-donenfeld D. A proof of concept study demonstrating that environmental levels of carbamazepine impair early stages of chick embryonic development. Environ Int. 2019;129:583-94.

22. Hamburger $\mathrm{V}$, Hamilton $\mathrm{H}$. A series of normal stages in the development of the chick embryo. J Morphol. 1951;88(1):49-92.

23. Castro MIAL, Lucena MGS, Silva CVNS, Xavier YKS, Barbosa-filho JM, Teles MMRS, et al. Acute toxicity and cytogenotoxicity of yangambin isolated from Ocotea duckei vattimo-gil. Phcog Res. 2020;12(4):444.

24. Turgut U, Kazan S, Cakin H, Ozak A. Valproic acid effect on neural tube defects is not prevented by concomitant folic acid supplementation: Early chick embryo model pilot study. Int J Dev Neurosci. 2019;78:45-8.

25. Araújo ICS, Leandro NSM, Mesquita MA, Café MB, Mello HHC, Gonzales E. Effect of incubator type and broiler breeder age on hatchability and chick quality. Braz J Poult Sci. 2016;18(SPE2):17-25.

26. Cobb-vantress. Incubation Management Guide Cobb. Cobb. 2008;1-46.

27. Lima LS, Barbosa-filho JM, Gutierrez SJC, Lima RMPL, Medeiros PL, Silva, EC. Riparin III effect on the development of neural tube embryos of Gallus gallus. Afr J of Pharm Pharmacol. 2017;11(14):178-85.

28. Wirth MJ, Ackels T, Kriebel A, Kriebel K, Mey J, Kuenzel T, et al. Expression Patterns of Chloride Transporters in the Auditory Brainstem of Developing Chicken. Hear Res. 2020;393:108013.

29. Pokhrel N, Ben-tal cohen E, Genin O, Sela-donenfeld D, Cinnamon Y. Cellular and morphological characterization of blastoderms from freshly laid broiler eggs. Poult Sci. 2017;96(12):4399-408

30. Pokhrel N, Ben-tal cohen E, Genin O, Ruzal M, Sela-donenfeld D, Cinnamon Y Effects of storage conditions on hatchability, embryonic survival and cytoarchitectural properties in broiler from young and old flocks. Poult Sci. 2018;97(4):1429-40

31. Ishikawa Y, Yamamoto $\mathrm{N}$, Yoshimoto $\mathrm{M}$, Ito $\mathrm{H}$. The primary brain vesicles revisited: Are the three primary vesicles (forebrain/midbrain/hindbrain) universal in vertebrates. Brain Behav Evolut. 2012;79(2):75-83.

32. Jiao YH, Liu M, Wang G, Li HY, Liu JS, Yang X, et al. EMT is the major target for okadaic acid-suppressed the development of neural crest cells in chick embryo. Ecotoxicol Environ Saf. 2019;180:192-201.

33. Liu M, Jin L, Yu J, Su Z, Sun Y, Liu Y, et al. Essential trace elements in umbilical cord tissue and risk for neural tube defects. Reprod Toxicol. 2020;98:149-56.

34. Özeren E, Er U, Güvenç Y, Demirci A, Arikök AT, Senveli E, et al. The effect 
of flurbiprofen on the development of anencephaly in early stage chicken embryos. Br J Neurosurg. 2015;29(2):265-71.

35. Xu G, Kemp PS, Hwu JA, Beagley AM, Bayly PV, Taber LA. Opening angles and material properties of the early embryonic chick brain. J Biomech Eng. 2010;132(1):011005

36. Hirashima M, Kobayashi T, Uchikawa M, Kondoh H, Araki M. Anteroventrally localized activity in the optic vesicle plays a crucial role in the optic development. Dev Biol. 2008;317(2):620-31.

37. Emon ST, Orakdogen M, Uslu S, Somay H. Effects of the popular food additive sodium benzoate on neural tube development in the chicken embryo. Turk Neurosurg. 2015;25(2):294-7.

38. Draga M, Heim K, Batke R, Wegele M, Pröls F, Scaal M. Somite development in the avian tail. J Anat. 2019;235(4):716-24.
39. Duess JW, Gosemann JH, Puri P, Thompson J. Teratogenesis in the chick embryo following post-gastrulation exposure to Y-27632-effect of Y-27632 on embryonic development. Toxicol Appl Pharmacol. 2020;409:115277.

40. Lee S, Gleeson JG. Closing in on Mechanisms of Open Neural Tube Defects. Trends Neurosci. 2020;43:519-32.

41. Tsujimura R, Mominoki K, Kinutani M, Shimokawa T, Doihara T, Nabeka $H_{\text {, }}$ et al. Sensory tract abnormality in the chick model of spina bifida. Neurosci Res. 2011;71(1):85-91.

42. Cinelli DP, Stoica I, Atwan F, Paran S. A rare presentation of Sacrococcygeal Teratoma as recurrent natal cleft abscess in childhood. J Pediatr Surg Case Rep. 2021;64:101727.

43. Nakamura M, Moriya K, Honda S, Ara M, Nishimura Y, Kon M, et al. Congenital urogenital sinus anomaly in a patient with sacrococcygeal teratoma. J Pediatr Surg Case Rep. 2020;61:101587.

\section{GRAPHICAL ABSTRACT}

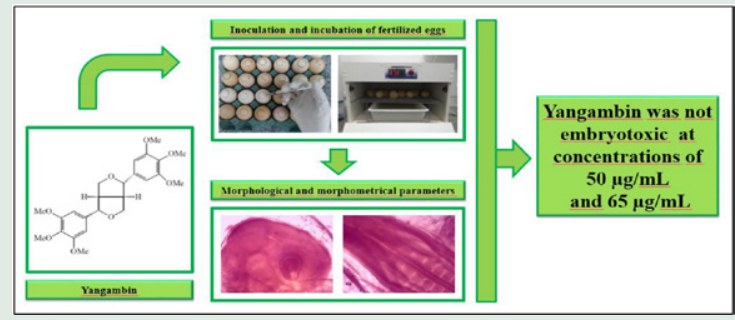

\section{SUMMARY}

- Yangambin isolated from Ocotea duckei Vattimo-Gil has several pharmacological activities.

- The aim of this study was to evaluate the embryotoxicity of yangambin in Gallus gallus domesticus embryos.

- Morphological and morphometrical parameters were adopted.

- Yangambin was not embryotoxic at concentrations of $50 \mu \mathrm{g} / \mathrm{ml}$ and $65 \mu \mathrm{g} / \mathrm{ml}$.

Cite this article: Silva TF, Castro MI, Lucena MG, Silva CV, Peixoto LR, Carvalho EA, Paz ST, Guimarães BL, Filho JM, Silva EC. Embryotoxicity of Yangambin Isolated from Ocotea duckei Vattimo-Gil in Gallus gallus domesticus Embryos. Pharmacog Res. $2021 ; 13(3): 135-9$. 